\title{
HUBUNGAN ANTARA PENDAPATAN, DAYA SAING DAN PEMBANGUNAN MANUSIA DI ASIA TENGGARA
}

\author{
Noor Zuhdiyaty \\ Fakultas Ekonomi dan Bisnis Universitas Brawijaya \\ Email: diyahzuhdiyaty@gmail.com
}

\begin{abstract}
Revenue, competitiveness and human development are important in supporting a country's economic development. This study aims to examine the relationship between income, competitiveness and human development in Southeast Asia during the period of five years from 2010-2014. This research uses quantitative approach with correlation test. This study was conducted on 8 (eight) countries in Southeast Asia. The results show that there is a relationship between income, competitiveness and human development, where competitiveness and human development have a strong relationship that is very strong compared to others.
\end{abstract}

Key words: Revenue, competitiveness, human development

\section{PENDAHULUAN}

embangunan ekonomi merupakan konsep dari pertumbuhan ekonomi (Atalay 2015). Konsep pertumbuhan dan pembangunan ekonomi sendiri memiliki keterkaitan untuk kemajuan ekonomi yang ada, dan ini merupakan hal yang penting oleh karena itu hal tersebut merupakan faktor utama kuantitatif untuk pengembangan ekonomi (Neamtu 2015). Pembangunan ekonomi juga konsep dimana banyak negara berkembang yang tertarik akan hal ini (Atalay 2015).

Negara berkembang adalah negara yang sedang membangun negara modern. Negara berkembang dengan sengaja melakukan perencanaan pembangunan ekonomi untuk memiliki kualitas hidup yang lebih sejahtera. Pembangunan ekonomi adalah proses untuk meningkatkan pendapatan perkapita (Prishardoyo 2008) atau gabungan faktor-faktor produksi yang dibuktikan dengan indikator makroekonomi produk nasional bruto dan pendapatan nasional secara riil, baik total dan per kapita (Neamtu 2015). 
Salah satu hal yang memiliki peran utama dalam pertumbuhan ekonomi pada perekonomian modern yaitu modal manusia. Modal manusia meliputi akumulasi investasi dalam pendidikan, ilmu pengetahuan, kesehatan, keamanan, kualitas hidup dan intelektual (Yakunina and Bychkov, 2015). Salah satu indeks yang menggambarkan modal manusia adalah IPM. IPM digunakan sebagai penilaian kuantitatif dasar modal manusia (Yakunina and Bychkov, 2015). Sementara dalam pengukuran sebuah kesejahteraan maka menggunakan daya saing (Herciu and Ogrean 2015). Selain itu daya saing digunakan untuk menggambarkan fenomena, produk sampingan dari pertumbuhan ekonomi, dan konsep integratif. Pada artikel ini penulis ingin mengetahui hubungan antara pendapatan yang diukur dari pendapatan perkapita, daya saing yang diukur dari GCI (Global competitiveness index) serta modal manusia yang diukur dari IPM (Indeks Pembangunan Manusia). Adapun lokasi penelitian adalah kawasan Asia pada Asia Tenggara dimana Asia Tenggara memainkan peran utama dalam Asia berkembang (Huggins and Izushi 2008).

\section{METODE PENELITIAN}

Metode yang digunakan dalam penelitian adalah kuantitatif dengan data sekunder. Sumber pengambilan data berasal dari WEF (Word Economic Forum), Word Bank, dan UNDP (United Nation Development Programme). Populasi dalam penelitian ini adalah beberapa negara berkembang di Asia Tenggara. Adapun pengumpulan data yang digunakan yaitu dokumentasi dengan melakukan pengamatan pada datadata, jurnal, literatur-literatur dan sumber lainnya yang mendukung penulisan artikel ini. Analisis yang digunakan adalah uji korelasi untuk melihat keeratan antar variabel.

Variabel yang digunakan GDP perkapita pada tahun 2010-2014, daya saing nasional yang diambil dari GCI tahun 2010-2014 serta HDI tahun 2010-2014 pada masing-masing negara.

Tabel 1. GDP perkapita, GCI, IMP se Asia Tenggara

\begin{tabular}{ccccc}
\hline NEGARA & Observasi & GDP Perkapita & GCI & IPM \\
\hline INDONESIA & 2010 & 3125 & 4.4 & 0.665 \\
& 2011 & 3648 & 4.4 & 0.671 \\
& 2012 & 3701 & 4.4 & 0.678 \\
& 2013 & 3632 & 4.5 & 0.681 \\
& 2014 & 3500 & 4.6 & 0.684 \\
\hline
\end{tabular}

QE Journal |Vol.06 - No. 02 July 2017 - 149 


\begin{tabular}{|c|c|c|c|c|}
\hline NEGARA & Observasi & GDP Perkapita & GCI & IPM \\
\hline \multirow[t]{6}{*}{ MALAYSIA } & 2010 & 9069 & 4.8 & 0.770 \\
\hline & 2011 & 10428 & 5.0 & 0.773 \\
\hline & 2012 & 10835 & 5.0 & 0.774 \\
\hline & 2013 & 10974 & 5.0 & 0.777 \\
\hline & 2014 & 11307 & 5.1 & 0.779 \\
\hline & 2010 & 1334 & 4.2 & 0.653 \\
\hline \multirow{4}{*}{ VIETNAM } & 2011 & 1543 & 4.2 & 0.657 \\
\hline & 2012 & 1755 & 4.1 & 0.660 \\
\hline & 2013 & 1908 & 4.1 & 0.663 \\
\hline & 2014 & 2052 & 4.2 & 0.666 \\
\hline \multirow[t]{5}{*}{ FILIPINA } & 2010 & 2145 & 4.0 & 0.645 \\
\hline & 2011 & 2372 & 4.0 & 0.653 \\
\hline & 2012 & 2605 & 4.2 & 0.657 \\
\hline & 2013 & 2787 & 4.3 & 0.664 \\
\hline & 2014 & 2873 & 4.4 & 0.668 \\
\hline \multirow[t]{5}{*}{ KAMBOJA } & 2010 & 783 & 3.6 & 0.536 \\
\hline & 2011 & 879 & 3.9 & 0.541 \\
\hline & 2012 & 946 & 4.0 & 0.546 \\
\hline & 2013 & 1025 & 4.0 & 0.550 \\
\hline & 2014 & 1095 & 3.9 & 0.555 \\
\hline \multirow{5}{*}{ THAILAND } & 2010 & 5112 & 4.5 & 0.716 \\
\hline & 2011 & 5539 & 4.5 & 0.721 \\
\hline & 2012 & 5915 & 4.5 & 0.724 \\
\hline & 2013 & 6225 & 4.6 & 0.724 \\
\hline & 2014 & 5970 & 4.7 & 0.726 \\
\hline \multirow[t]{5}{*}{ TIMOR LESTE } & 2010 & 876 & 3.2 & 0.600 \\
\hline & 2011 & 1016 & 3.3 & 0.611 \\
\hline & 2012 & 1127 & 3.2 & 0.604 \\
\hline & 2013 & 1118 & 2.8 & 0.601 \\
\hline & 2014 & 1131 & 3.1 & 0.595 \\
\hline \multirow[t]{5}{*}{ SINGAPURA } & 2010 & 46570 & 5.5 & 0.897 \\
\hline & 2011 & 53094 & 5.6 & 0.903 \\
\hline & 2012 & 54451 & 5.7 & 0.905 \\
\hline & 2013 & 55618 & 5.6 & 0.909 \\
\hline & 2014 & 56007 & 5.7 & 0.912 \\
\hline
\end{tabular}

Sumber : WEF, Word Bank, UNDP

Penelitian ini merupakan pengembangan dari penelitian sebelumnya yang telah dilakukan oleh Herciu. Penelitian sebelumnya menjelaskan bagaimana hubungan antara gdp perkapita, gci dan nici dengan sumber 40 negara dari berbagai belahan benua dan dalam kurun wakt satu tahun. Perbedaannya adalah bahwa penelitian ini hanya fokus pada negara- 
negara di Asia tenggara saja dengan sampel 8 negara dan dalam kurun waktu lima tahunan yaitu mulai tahun 2010-2014.

Pada penelitian ini kami juga tidak menggunakan variabel NICI melainkan IPM yang bersumber dari UNDP, dimana IPM yang dikembangkan oleh Program Pembangunan PBB (UNDP) adalah indikator yang paling banyak digunakan dan dibahas untuk mengetahui kondisi manusia di berbagai negara (Ram 2009). Indeks Pembangunan Manusia (IPM) merupakan indeks yang komprehensif, yang mencirikan tingkat manusia pembangunan di negara dan wilayah negeri tersebut. Indeks ini melekat dalam pengukuran negara prestasi dalam hal kesehatan dan umur panjang, pendidikan dan pendapatan yang sebenarnya warganya. (Yakunina).

Adapun Indeks daya saing global memiliki dua belas pilar, yaitu kelembagaan,infrastruktur, lingkungan makroekonomi, kesehatan dan pendidikan dasar, pendidikan tinggi dan pelatihan, efisiensi pasar yang baik, efisiensi pasar tenaga kerja, pengembangan pasar keuangan, kesiapan teknologi, ukuran pasar, bisnis shopistication,dan innovasi. Sedangkan IPM terdiri dari tiga dimensi yaitu memiliki hidup yang lama dan sehat, mendapat pengetahuan dan standar hidup yang layak.

Tabel 2. Korelasi antara GDP perkapita, GCI dan IPM

\begin{tabular}{lccc}
\hline & Korelasi Pearson & $\mathbf{R}^{\mathbf{2}}$ & Probabilitas \\
\hline $\begin{array}{l}\text { GDP perkapita } \\
\text { dengan GCI }\end{array}$ & 0.766763 & 0.587925 & $<0.001$ \\
\hline $\begin{array}{l}\text { GDP Perkapita } \\
\text { dengan IPM }\end{array}$ & 0.863773 & 0.746103 & $<0.001$ \\
\hline GCI dengan IPM & 0.896332 & 0.803411 & $<0.001$
\end{tabular}

Sumber : Diolah oleh Peneliti.

Pada tabel tersebut ditunjukkan bahwa hubungan antara GDP perkapita dengan GCI memiliki korelasi yang cukup tinggi dengan nilai korelasi pearson sebesar 0.766763 , sama dengan penelitian sebelumnya. Hal ini menandakan bahwa pada pembangunan ekonomi di Asia Tenggara antara pendapatan dan daya saing memiliki keeratan yang cukup tinggi hal ini 
juga dijelaskan dalam probabilitas < 0.001 dan ditunjukkan pada nilai Rsquare sebesar 0.567925 .

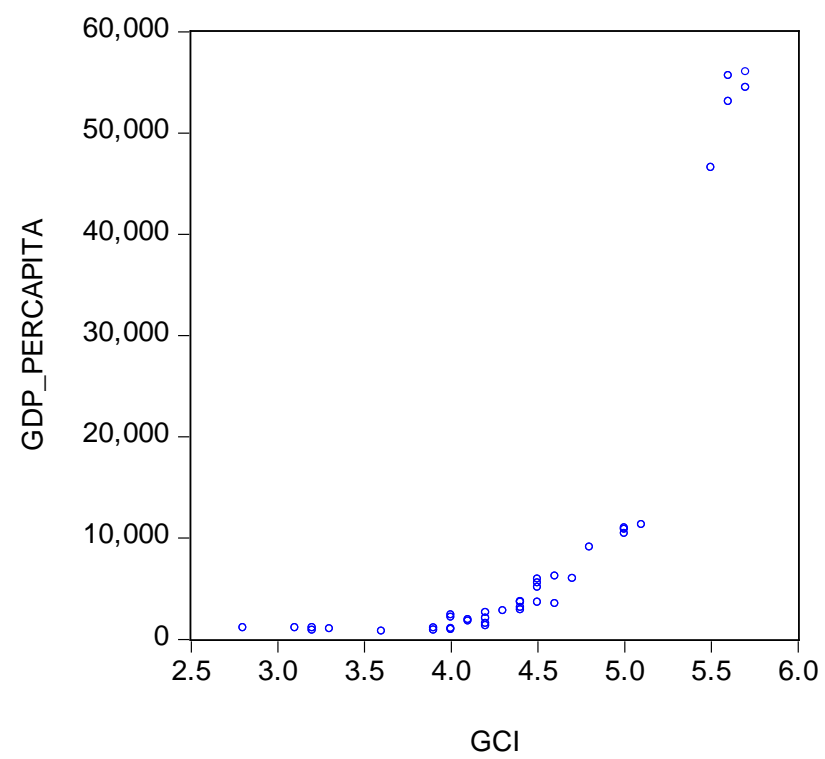

Gambar 1. GDP Perkapita dan GCI

Pada gambar tersebut juga dapat dilihat bahwa antara GDP perkapita dengan GCI menunjukkan korelasi yang positif dimana adanya peningkatan gdp_perkapita diikuti dengan peningkatan gci meskipun tidak secara pelan-pelan.

Gambar 1 juga menjelaskan bahwa adanya jarak yang cukup tinggi pada sebaran yang paling atas dimana sebaran tersebut diduduki oleh negara Singapura yang memiliki latar belakang negara maju, yang berarti negara maju memiliki pendapatan yang lebih tinggi dibandingkan dengan negara berkembang (Herciu and Ogrean 2015)

Sedangkan antara GDP perkapita dengan IPM memiliki korelasi yang kuat hal ini juga dapat dilihat dari nilai probabilitas kurang dari 0.001 dan $R$ square sebesar 0.746103. Gambar 2 menggambarkan bahwa ada hubungan positif antara GDP perkapita dengan IPM, pola yang ada hampir sama dengan antara GDP perkapita dengan GCI. 


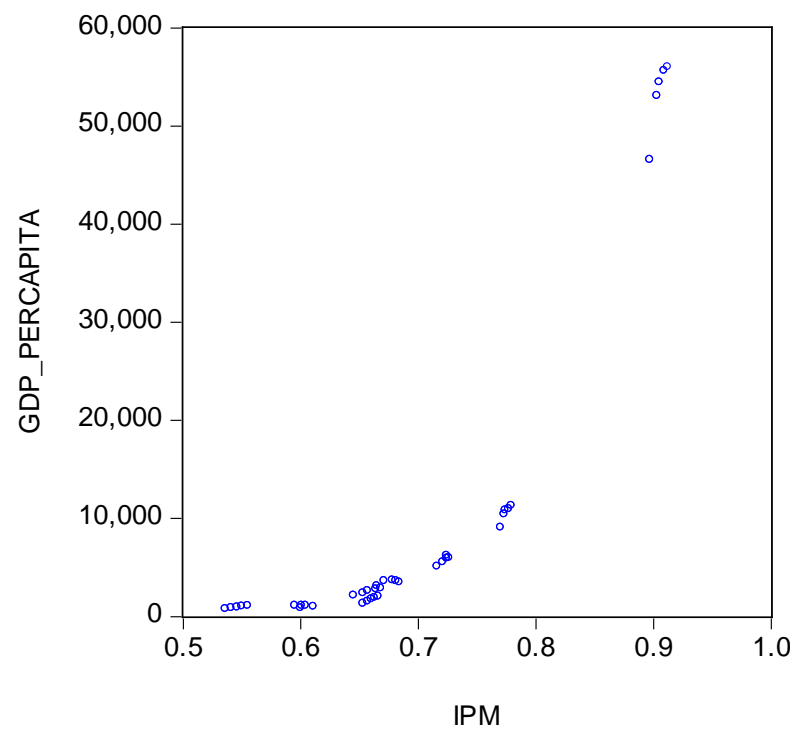

Gambar 2. GDP Perkapita dan IPM

Untuk korelasi antara GCI dan IPM sangat kuat dibuktikan dengan nilai dari korelasi pearson sebesar 0.896332 dan Rsquare 0.803411 serta nilai probibilitas kurang dari 0.001 yang menandakan adanya hubungan antara kedua variabel tersebut.Pendapatan perkapita sendiri merupakan determinan yang penting untuk pembangunan manusia. (Peneva \& Ram 2012)

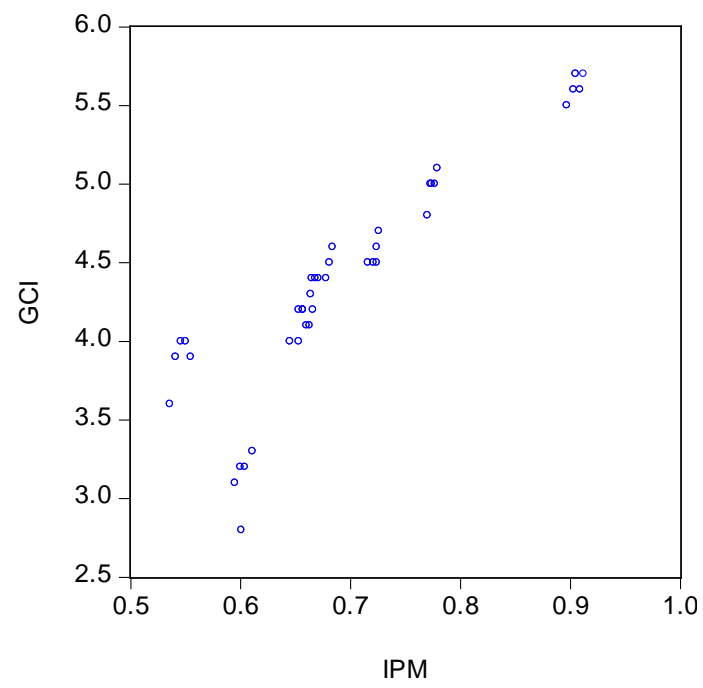

Gambar 3. GCI dan IPM

QE Journal | Vol.06 - N 0.02 July 2017 - 153 
Pada gambar 3 tersebut dapat dilihat bahwa korelasi antara GCI dan IPM memiliki slope yang positif yang berarti bahwa antara GCI dan IPM memiliki hubungan yang erat dan sama-sama tinggi. hal tersebut menandakan bahawa di Asia Tenggara ketika IPM semakin tinggi maka diperkirakan juga akan memiliki GCI yang tinggi pula

\section{SIMPULAN DAN SARAN}

Terdapat hubungan antara ketiga variabel tersebut. GDP perkapita dengan GCI memiliki huungan yang cukup erat. GDP perkapita dengan IPM memiliki hubungan yang sangat erat, begitu pula dengan GCI dan IPM memiliki hubungan yang sangat erat. Diantara ketiga variabel tersebut yang sama-sama memiliki nilai yang tinggi diperoleh Singapura dimana negara tersebut adalah satu-satunya negara maju yang berada pada kawasan Asia Tenggara, sementara lainnya adalah negara berkembang menengah dan menengah kebawah. Hasil korelasi yang menunjukkan tingkat keeratan paling tinggi adalah antara GDP perkapita dan IPM serta GCI dan IPM yang berarti bahwa agar pembangunan ekonomi suatu negara semakin maju agar meningkatkan ketiga variabel tersebut utamanya IPM yang nantinya hal tersebut dapat meningkatkan GCI yang berujung pada mningkatnya pendapatan perkapita sehingga pembangunan ekonomi akan mengalami kemajuan.

\section{DAFTAR PUSTAKA}

Atalay, Refika. 2015. "ScienceDirect The Education and the Human Capital to Get Rid of the Middle-Income Trap and to Provide the Economic Development." Procedia -Social and Behavioral Sciences 174: 969-76. http://dx.doi.org/10.1016/j.sbspro.2015.01.720.

Herciu, Mihaela, and Claudia Ogrean. 2015. "Wealth, Competitiveness, and Intellectual Capital - Sources for Economic Development." Procedia Economics and Finance 27(15): 556-66. http://www.sciencedirect.com/science/article/pii/\$2212567115010 333.

Huggins, Robert, and Hiro Izushi. 2008. "Benchmarking the Knowledge Competitiveness of the Globe's High-Performing Regions 
Competitiveness Index." Competitiveness Review: An International Business Journal 18(1/2): 70-86.

Neamtu. 2015. "Education, the Economic Development Pillar." Procedia Social and Behavioral Sciences 180(November 2014): 413-20. http://www.sciencedirect.com/science/article/pii S1877042815014 846.

Peneva, D. \& Ram, R., 2012. Trade policy and human development: a cross-country perspective. International Journal of Social Economics, 40(1), pp.51-67. Available at: http:/www.emeraldinsight.com/doi/10.1108/03068291311283436.

Prishardoyo, Bambang. 2008. Analisis Tingkat Pertumbuhan Ekonomi dan Potensi Ekonomi Terhadap Produk Regional Domestik Bruto (PDRB) Kabupaten PATI Tahun 2000-2005. Semarang : Fakultas Ekonomi Unnes ISSN 1979-715X.

Ram, Rati. 2009. "Intercountry Inequality in Human Development: A 30Year Perspective." Journal of Economic Studies 36(5): 481-89. http://www.emeraldinsight.com/10.1108/01443580910992393.

Schwab, K. et al., 2014. The Global Competitiveness Report, Available at: http:/wwww3.weforum.org/docs MEF_GlobalCompetitivenessRe port_2014-15.pdf.

Schwab, K., 2015. The global competitiveness report 2015-2016, Available at: www.weforum.org/gcr.

Schwab, K., Sala-i-Martin, X. \& Greenhill, R., 2010. The global competitiveness report 2009-2010, Available at: http:/wwww.weforum.org/pdf/GCR09/GCR20092010fullreport.pd f\%5Cnhttp://www.weforum.org/pdf/Global_Competitiveness_Re ports/Reports/factsheet_gcr03.pdf.

Online, diakses 28 November 2016. http:/hdr.undp.org/en/composite/HDI

Online, diakses $28 \quad 2016$. http://data.worldbank.org/indicator NY.GDP.PCAP.CD

Yakunina RP, and Bychkov GA. 2015. "ScienceDirect Correlation Analysis Of The Components Of The Human Development Index Across 
Countries." Procedia Economics and Finance 24(July): 766-71. http://dx.doi.org/10.1016/\$2212-5671(15)00692-9.

World Economic Forum, 2007. The Global Competitiveness Report 20062007. , p.598.

World Economic Forum, 2015. The Global Competitiveness Report The Global Competitiveness Report, 